\title{
RADIATIVE TRANSITIONS BETWEEN LOWEST AUTOIONIZING STATES IN SODIUM
}

\author{
A. Kupliauskiené ${ }^{\mathrm{a}}$, P. Bogdanovich ${ }^{\mathrm{a}}$, and A. Borovik ${ }^{\mathrm{b}}$ \\ ${ }^{a}$ Institute of Theoretical Physics and Astronomy of Vilnius University, A. Goštauto 12, LT-01108 Vilnius, Lithuania \\ E-mail: akupl@itpa.lt \\ ${ }^{\mathrm{b}}$ Institute of Electron Physics, National Academy of Sciences of Ukraine, Universitetska 21, UA-88017 Uzhgorod, Ukraine \\ E-mail: sasha@aborovik.uzhgorod.ua
}

Received 14 February 2007

\begin{abstract}
The wavelengths and radiative transition probabilities for the transitions $2 p^{5} 3 s 3 p L S J \rightarrow 2 p^{5} 3 s^{2}{ }^{2} \mathrm{P}_{1 / 2,3 / 2}$ and $2 p^{5} 3 s 3 p L S J \rightarrow 2 p^{6} 3 p^{2} \mathrm{P}_{1 / 2,3 / 2}$ in $\mathrm{Na}$ atoms are calculated by using large scale configuration interaction approximation. The autoionization probabilities and electron impact excitation cross-sections for the $2 p^{5} 3 s 3 p L S J$ levels are also calculated in single configuration intermediate coupling approach. The obtained results are used for evaluation of the role of radiative cascade transitions from the $2 p^{5} 3 s 3 p L S J$ doublets in population of the $2 p^{5} 3 s^{2}{ }^{2} \mathrm{P}_{1 / 2,3 / 2}$ lowest autoionizing levels.
\end{abstract}

Keywords: energy spectra, correlation corrections, transition probabilities, atomic excited states, electron impact excitation of atoms

PACS: 31.15.Ar, 31.25.Jf, 31.50.Df, 21.10.Ft, 34.80.Dp

\section{Introduction}

In ejected-electron excitation functions for the lowest $2 p^{5} 3 s^{2}{ }^{2} \mathrm{P}_{3 / 2}$ and ${ }^{2} \mathrm{P}_{1 / 2}$ autoionizing states in sodium [1], a strong resonance structure was revealed in the impact energy regions of 32-33 and 36.5$40.0 \mathrm{eV}$. However, recent $R$-matrix (close-coupling) calculations [2] did not confirm the existence of negative ion resonances at these energies. Another process, which may cause the observed structure, is the cascade population of the $2 p^{5} 3 s^{2}$ levels by the radiative transitions from the high-lying doublets. Earlier such a transition $(\lambda=434.3 \mathrm{~nm})$ was found between the $2 p^{5} 3 s\left({ }^{1} \mathrm{P}\right) 3 p^{2} \mathrm{P}_{3 / 2}$ and $2 p^{5} 3 s^{2}{ }^{2} \mathrm{P}_{3 / 2}$ autoionizing states in beam-foil excitation spectra [3]. In order to evaluate the real role of the radiative cascades in excitation of the lowest autoionizing doublet levels in sodium, the data on excitation and decay parameters for the $2 p^{5} 3 s n p, 2 p^{5} 3 p n d, 2 p^{5} 3 d n p$, and $2 p^{5} 4 s n p$ even configurations are needed.

For the investigation of core-excited autoionizing states of $\mathrm{Na}$, a number of experimental [1,4-11] and theoretical $[12,13]$ works was devoted. The absorption spectrum was registered by Wolf et al [4], Connerade et al [5], Sugar et al [6], and Baig et al [7]. The ejected-electron spectra were also studied by dif- ferent experimental methods $[1,8-10]$. The radiative decay of the $2 p^{5} 3 s 3 p$ autoionizing states was studied by Zhmenjak et al [11] in electron-atom collisions. Energy levels and lifetimes for some core-excited quartet states of $\mathrm{Na}$ were calculated by applying multiconfiguration Hartree-Fock (MCHF) approximation [12]. The systematic studies of the $\mathrm{Na} 2 p^{5} 3 s n l$ autoionizing (AI) states were performed by Zatsarinny and Bandurina [13]. They have used the configuration interaction (CI) approach. The set of radial orbitals was obtained from Hartree-Fock calculation of $2 p^{5} n l$ states of $\mathrm{Na}^{+}$ within the fixed-core average energy approximation. These orbitals were used to make up the basis sets for the CI calculations of autoionizing states as described in $[14,15]$. To achieve a better agreement between the calculated and experimental energies of AI levels, the radial orbitals of valence $n l$ electrons were obtained by using a model potential with adjustable parameters. The data obtained were accurate enough to extend and clarify considerably the classification of lines in existing photoabsorption [4-7] and ejected-electron spectra [9].

The aim of the present work was an examination of the role of radiative transitions from the $2 p^{5} 3 s 3 p L S J$ doublet states in electron impact excitation of the $2 p^{5} 3 s^{2} \quad{ }^{2} \mathrm{P}_{1 / 2,3 / 2}$ lowest autoionizing states. The 
second aim was a pure theoretical $a b$ initio investigation of the lowest autoionizing states in sodium avoiding the semi-empirical corrections. We have calculated the wavelengths and radiative transition probabilities for the transitions $2 p^{5} 3 s 3 p L S J \rightarrow 2 p^{5} 3 s^{2}{ }^{2} \mathrm{P}_{1 / 2,3 / 2}$ and $2 p^{5} 3 s 3 p L S J \rightarrow 2 p^{6} 3 p{ }^{2} \mathrm{P}_{1 / 2,3 / 2}$ as well as the autoionization probabilities and electron impact excitation cross-sections for the $2 p^{5} 3 s 3 p L S J$ levels. The description of methods used for the calculations is presented in the second section. The results of calculations are discussed in the third section.

\section{Method of calculations}

The theoretical investigation of the energies and radiative transition probabilities in $\mathrm{Na}$ atom is performed by using the method fully described and successfully applied in our previous papers [16-23]. While calculating the energy spectra, the relativistic effects were taken into account within the traditional Breit-Pauli approximation, i.e. the spin-orbit and other relativistic one- and two-electron interactions accurate up to the square of the fine structure constant were included.

The correlation corrections were taken into account by the CI technique. The basis set of non-relativistic radial orbitals was constructed as follows. The radial orbitals of electrons with $n \leq 3$ were determined by solving the Hartree-Fock equations [24]. For describing the excitations into the virtual states with a higher principal quantum number the transformed radial orbitals with a variable parameter (TROs) [17] were employed. Our experience in the application of this method to different atoms and ions (see Refs. [18-23]) reveals that the employment of such radial orbitals enables one to take into account the correlation corrections within the CI method quite efficiently. We study all the configurations of an odd parity (or those of an even parity) simultaneously; in fact, the levels of these configurations are located comparatively close and the improvement of the levels of one configuration has an influence on the locations of the levels of configurations with the same parity. Such approach allows us to take into account not only one- and two-electron virtual excitations according to the two-electron Hamiltonian used, but also the excitations of a higher order. We must note that such an approach is very important for the calculation of the oscillator strengths and transition probabilities of the forbidden one-electron transitions, as well as for the determination of characteristics of the two-electron transitions.
TROs with $n \leq 13$ and $l \leq 10$ are used in the calculations of $\mathrm{Na}$ I energy spectra. It is easy to get a wide basis set of radial orbitals obtained by the method described in [17] and to generate many admixed configurations by a virtual excitation of one or two electrons from $2 l$ and $3 l$ shells, but then the rank of the energy operator matrix becomes very high, too. The total number of the admixed configurations is 13241 for odd configurations $2 p^{5} 3 s^{2}, 2 p^{6} 3 p, 2 p^{5} 3 s 3 d$, and $2 p^{5} 3 p^{2}$, and 9500 for even configurations $2 p^{6} 3 s, 2 p^{5} 3 s 3 p$, and $2 p^{6} 3 d$. It is necessary to reduce the number of admixed configurations, because the accounting of a great number of admixed configurations exceeds the possibilities of a single computer (the PC) that we use, and not all of the admixed configurations are important. In this calculation the admixed configurations were selected according to their contribution to the wavefunction of the adjusted configurations. These contributions were evaluated in the second order of the perturbation theory as described in papers $[25,26]$. These methods are based on the use of the second-order perturbation theory and the analytical expressions for sums of squares of the interconfigurational matrix elements and for the averaged energy differences between the adjusted and admixed configurations as well. They provide the balance of the accounted correlation corrections when the same selection criteria for each configuration are used. All configurations with the averaged weights higher than $2.0 \cdot 10^{-8}$ are included into the set of admixed configurations. For the odd configurations the number of admixed configurations is 2174 , for the even configurations it is 2000. As it is shown in [27], such selection criterion is sufficient for the accurate calculations. The selection of the admixed configurations is performed by using the program SELECTCONF [28].

The total number of the configuration state functions (CSFs) for each configuration parity was found to be very large; these numbers were greater than $10^{6}$ for even configurations and greater than 79000 for odd ones. The reduction of this number was achieved in the way described in [29] and used in our previous calculations. As a result, 62657 CSFs were obtained for two even adjusted configurations $\left(2 p^{6} 3 s, 2 p^{5} 3 s 3 p\right)$ and 29997 CSFs for two odd ones $\left(2 p^{5} 3 s^{2}, 2 p^{6} 3 p\right)$. The virtually excited electrons were placed at the beginning of the list of the active shells and some restrictions were put on their intermediate and final $L S$ momenta. This method is realized in program ATOTERM [30].

The multiconfiguration wave functions obtained by diagonalizing the matrix of the energy operator were used to compute the matrix elements of the electron 
Table 1. Calculated and experimental energies $E$ (in $\mathrm{eV}$ ) with respect to the ground state of $\mathrm{Na}$, and autoionization probabilities $A$ (in s ${ }^{-1}$ ) for the $2 p^{5} 3 s^{2}{ }^{2} \mathrm{P}_{J}$ and $2 p^{5} 3 s\left(L_{1} S_{1}\right) 3 p L S J$ states.

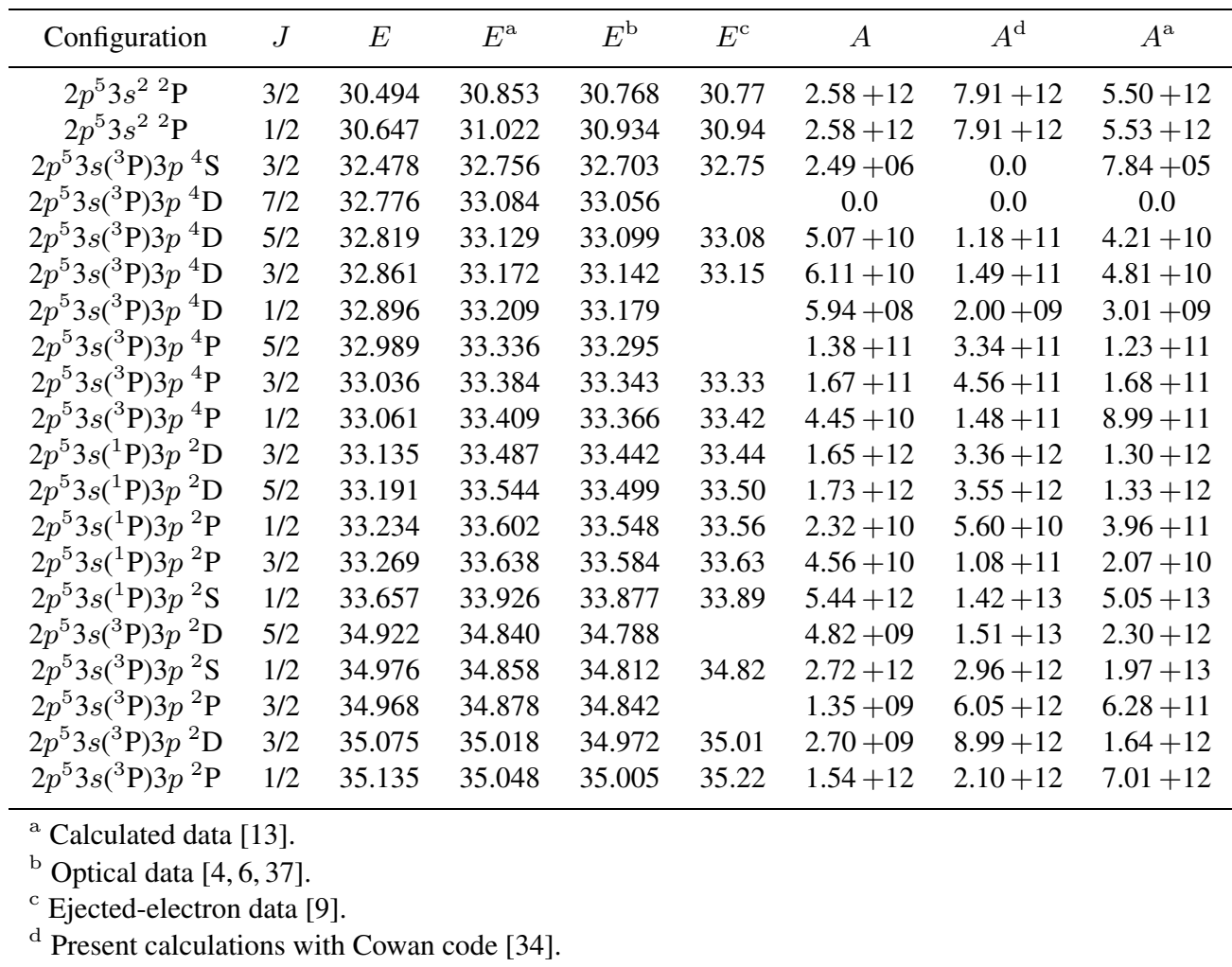

transition operator and, correspondingly, oscillator strengths and probabilities of the electric dipole transitions.

The electric dipole transitions were evaluated using two forms of the transition operator: 'length' (L) and 'velocity' (V). The radiative lifetimes are presented in both forms and that enables one to compare the results obtained using different forms. As it is known, the coincidence of the results obtained with these two forms of the operator serves as a reliability criterion for the data obtained by CI, when the basis of the admixed configuration included into configuration interaction is large. In the computations, along with our own computer codes, we also employed the program [31] for calculating the angular parts of the energy operator matrix elements and the programs $[32,33]$ for evaluating the characteristics of electronic transitions.

The autoionization probabilities were calculated by using the Cowan code [34] and Kupliauskienè code [35]. The wave functions were obtained in a singleconfiguration intermediate coupling approximation with Breit-Pauli relativistic corrections by using a complex of computer programs [24]. The electronimpact excitation cross-sections were calculated in distorted wave (DW) with exchange approximation. The wave functions obtained in the intermediate coupling approximation with Breit-Pauli relativistic corrections from the complex of codes [22] were used for the calculation of cross-sections [36].

\section{Results and discussions}

The calculated energies $E$ (in eV) of the $2 p^{5} 3 s^{2}{ }^{2} \mathrm{P}_{J}$ and $2 p^{5} 3 s\left(L_{1} S_{1}\right) 3 p L S J$ states and experimental data $[4,6,37]$ as well as theoretical values from [13] with respect to the ground state of $\mathrm{Na}$ are presented in Table 1. The autoionization probabilities $A$ (in $\mathrm{s}^{-1}$ ) calculated in the present work by using our own and Cowan [34] computer programs and those taken from [13] are also included in the Table 1 . The results of Table 1 show that the energy spectrum calculated in the present work is a bit wider than that obtained including a model potential [13], therefore, the agreement between calculated and experimental spectra is better for upper levels. The ordering of the energy levels obtained coincides with that calculated in [13] and experimental one [4-6,37], except for the $2 p^{5} 3 s\left({ }^{3} \mathrm{P}\right) 3 p{ }^{2} \mathrm{~S}_{1 / 2},{ }^{2} \mathrm{P}_{1 / 2}$ levels, which are obtained interchanged in our calculations. The experimental energies are in better agreement with those calculated in [13] than in the present work. They stand between the energies calculated in the present work and in [13]. 
Table 2. Wavelengths $\lambda$ (in $\mathrm{nm}$ ) and probabilities $A$ (in s${ }^{-1}$ ) calculated in configuration interaction approximation (length $\mathrm{L}$ and velocity $\mathrm{V}$ forms), expected values of wavelengths $\lambda_{\exp }$ calculated by using experimental energies of levels $[4,6,37]$, and fluorescence yields $\gamma$ for the transition from $2 p^{5} 3 s\left(L_{1} S_{1}\right) 3 p L S J$ to $2 p^{5} 3 s^{2}{ }^{2} \mathrm{P}_{J 0}$ states in $\mathrm{Na}$.

\begin{tabular}{|c|c|c|c|c|c|c|c|}
\hline$\left(L_{1} S_{1}\right) L S$ & $J$ & $J_{0}$ & $\lambda$ & $\lambda_{\exp }$ & $A^{\mathrm{L}}$ & $A^{\mathrm{V}}$ & $\gamma$ \\
\hline \multirow[t]{2}{*}{$\left({ }^{1} \mathrm{P}\right)^{2} \mathrm{~S}$} & $1 / 2$ & $3 / 2$ & 392.0 & 398.8 & $1.28+7$ & $1.01+7$ & $2.4-4$ \\
\hline & $1 / 2$ & $1 / 2$ & 411.9 & 421.3 & $4.70+6$ & $3.73+6$ & $8.6-5$ \\
\hline \multirow[t]{4}{*}{$\left({ }^{1} \mathrm{P}\right)^{2} \mathrm{P}$} & $1 / 2$ & $1 / 2$ & 479.3 & 474.3 & $3.79+5$ & $5.61+5$ & $1.5-5$ \\
\hline & $1 / 2$ & $3 / 2$ & 452.5 & 446.0 & $5.62+5$ & $6.36+5$ & $2.3-5$ \\
\hline & $3 / 2$ & $1 / 2$ & 472.9 & 467.9 & $9.07+4$ & $1.19+5$ & $1.9-6$ \\
\hline & $3 / 2$ & $3 / 2$ & 446.7 & 440.3 & $9.92+5$ & $1.24+6$ & $2.1-5$ \\
\hline \multirow[t]{3}{*}{$\left({ }^{1} \mathrm{P}\right)^{2} \mathrm{D}$} & $3 / 2$ & $1 / 2$ & 498.2 & 494.4 & $1.93+5$ & $3.22+5$ & $1.2-7$ \\
\hline & $3 / 2$ & $3 / 2$ & 469.3 & 463.7 & $1.67+4$ & $2.82+4$ & $1.0-8$ \\
\hline & $5 / 2$ & $3 / 2$ & 459.7 & 454.0 & $3.44+5$ & $5.15+5$ & $2.0-7$ \\
\hline \multirow[t]{2}{*}{$\left({ }^{3} \mathrm{P}\right)^{2} \mathrm{~S}$} & $1 / 2$ & $1 / 2$ & 286.4 & 319.7 & $1.89+6$ & $2.39+6$ & $6.9-7$ \\
\hline & $1 / 2$ & $3 / 2$ & 276.6 & 306.6 & $5.70+8$ & $4.64+8$ & $2.1-4$ \\
\hline \multirow[t]{4}{*}{$\left({ }^{3} \mathrm{P}\right)^{2} \mathrm{P}$} & $1 / 2$ & $1 / 2$ & 276.3 & 304.6 & $5.97+8$ & $4.72+8$ & $2.2-4$ \\
\hline & $1 / 2$ & $3 / 2$ & 267.1 & 292.6 & $5.77+6$ & $3.41+6$ & $2.1-6$ \\
\hline & $3 / 2$ & $1 / 2$ & 286.9 & 317.3 & $3.12+7$ & $2.31+7$ & 0.01 \\
\hline & $3 / 2$ & $3 / 2$ & 277.1 & 304.3 & $5.24+8$ & $4.06+8$ & 0.48 \\
\hline \multirow[t]{3}{*}{$\left({ }^{3} \mathrm{P}\right)^{2} \mathrm{D}$} & $3 / 2$ & $1 / 2$ & 280.0 & 307.0 & $4.67+8$ & $3.60+8$ & 0.1 \\
\hline & $3 / 2$ & $3 / 2$ & 270.6 & 294.9 & $6.84+7$ & $5.37+7$ & 0.015 \\
\hline & $5 / 2$ & $3 / 2$ & 280.0 & 308.4 & $4.82+8$ & $3.66+8$ & $3.1-4$ \\
\hline \multirow[t]{2}{*}{$\left({ }^{3} \mathrm{P}\right){ }^{4} \mathrm{~S}$} & $3 / 2$ & $1 / 2$ & 677.0 & 700.9 & $7.67+1$ & $1.54+2$ & $1.3-5$ \\
\hline & $3 / 2$ & $3 / 2$ & 624.7 & 640.8 & $5.23+2$ & $9.12+2$ & $8.7-5$ \\
\hline \multirow[t]{5}{*}{$\left({ }^{3} \mathrm{P}\right){ }^{4} \mathrm{P}$} & $5 / 2$ & $3 / 2$ & 496.8 & 490.6 & $1.93+4$ & $3.20+4$ & $1.4-7$ \\
\hline & $3 / 2$ & $3 / 2$ & 487.6 & 481.5 & $7.01+3$ & $8.76+3$ & $4.2-7$ \\
\hline & $3 / 2$ & $1 / 2$ & 518.9 & 514.7 & $3.84+4$ & $6.58+4$ & $2.3-7$ \\
\hline & $1 / 2$ & $3 / 2$ & 483.0 & 477.2 & $2.65+4$ & $1.50+4$ & $1.6-7$ \\
\hline & $1 / 2$ & $1 / 2$ & 513.6 & 509.8 & $3.01+4$ & $2.71+4$ & $1.8-7$ \\
\hline \multirow[t]{5}{*}{$\left({ }^{3} \mathrm{P}\right){ }^{4} \mathrm{D}$} & $5 / 2$ & $3 / 2$ & 533.2 & 531.9 & $5.29+3$ & $1.01+4$ & $1.0-7$ \\
\hline & $3 / 2$ & $3 / 2$ & 523.8 & 522.3 & $1.03+4$ & $1.63+4$ & $1.7-7$ \\
\hline & $3 / 2$ & $1 / 2$ & 560.0 & 561.5 & $1.25+3$ & $2.99+3$ & $2.0-8$ \\
\hline & $1 / 2$ & $3 / 2$ & 516.0 & 514.3 & $3.53+3$ & $5.77+3$ & $5.5-6$ \\
\hline & $1 / 2$ & $1 / 2$ & 551.1 & 552.3 & $9.07+3$ & $1.36+4$ & $1.4-5$ \\
\hline
\end{tabular}

An inspection of the autoionization probabilities from Table 1 leads to the conclusion that single-configuration intermediate coupling results of the present work are in better agreement with those of [13] than those calculated with Cowan program [34]. For the $2 p^{5} 3 s\left({ }^{3} \mathrm{P}\right) 3 p{ }^{2} \mathrm{D}_{5 / 2,3 / 2}$ and ${ }^{2} \mathrm{P}_{3 / 2}$ levels an order of 2 discrepancy between our autoionization (AI) probabilities and those of [13] as well as calculated with Cowan program was obtained. The Coulomb autoionization of the $2 p^{5} 3 s 3 p^{2} \mathrm{P}_{J}$ and $2 p^{5} 3 s 3 p^{4} L_{J}$ states is forbidden due to parity arguments. The non-zero values of AI probabilities for these levels are obtained due to admixture of the $2 p^{5} 3 s 3 p{ }^{2} \mathrm{~S}_{1 / 2}$ and ${ }^{2} \mathrm{D}_{1 / 2,3 / 2}$ states. Therefore, the values of the AI probabilities from these states are smaller than those of allowed transitions (see
Table 1). But the values of AI probabilities strongly depend on the coefficients of the intermediate expansion, and strong mixture of terms results in large values of calculated probabilities for the states the autoionization from which is forbidden in pure $L S$ approximation.

The wavelengths and radiative decay probabilities for the transitions from $2 p^{5} 3 s\left(L_{1} S_{1}\right) 3 p L S J$ to $2 p^{5} 3 s^{2}$ ${ }^{2} \mathrm{P}_{J 0}$ states and from $2 p^{5} 3 s\left(L_{1} S_{1}\right) 3 p L S J$ to $2 p^{6} 3 p$ ${ }^{2} \mathrm{P}_{J 0}$ states calculated in $\mathrm{CI}$ approximation (length $\mathrm{L}$ and velocity $\mathrm{V}$ forms) as well as fluorescence yields $\gamma$ are presented in Tables 2 and 3, respectively. The AI states can decay via both radiative and autoionization transitions. The competition between these decay channels decreases the number of atoms populating the lower lying states under investigation. The probability 
Table 3. Wavelengths $\lambda$ (in $\mathrm{nm}$ ) and probabilities $A$ (in s ${ }^{-1}$ ) calculated in configuration interaction approximation (length $\mathrm{L}$ and velocity $\mathrm{V}$ forms) and fluorescence yields $\gamma$ for the transition from $2 p^{5} 3 s\left(L_{1} S_{1}\right) 3 p L S J$ to $2 p^{6} 3 p^{2} \mathrm{P}_{J 0}$ states in Na.

\begin{tabular}{|c|c|c|c|c|c|c|}
\hline$\left(L_{1} S_{1}\right) L S$ & $J$ & $J_{0}$ & $\lambda$ & $A^{\mathrm{L}}$ & $A^{\mathrm{V}}$ & $\gamma$ \\
\hline \multirow[t]{2}{*}{$\left({ }^{1} \mathrm{P}\right)^{2} \mathrm{~S}$} & $1 / 2$ & $1 / 2$ & 39.38 & $9.08+8$ & $8.72+8$ & $1.7-5$ \\
\hline & $1 / 2$ & $3 / 2$ & 39.39 & $1.40+9$ & $1.35+9$ & $2.4-4$ \\
\hline \multirow[t]{4}{*}{$\left({ }^{1} \mathrm{P}\right)^{2} \mathrm{P}$} & $1 / 2$ & $1 / 2$ & 39.92 & $8.61+8$ & $8.23+8$ & 0.035 \\
\hline & $1 / 2$ & $3 / 2$ & 39.92 & $6.39+8$ & $5.98+8$ & 0.026 \\
\hline & $3 / 2$ & $1 / 2$ & 39.87 & $4.40+8$ & $4.10+8$ & $9.4-3$ \\
\hline & $3 / 2$ & $3 / 2$ & 39.88 & $1.04+9$ & $9.92+8$ & 0.022 \\
\hline \multirow[t]{3}{*}{$\left({ }^{1} \mathrm{P}\right)^{2} \mathrm{D}$} & $3 / 2$ & $1 / 2$ & 40.04 & $1.18+9$ & $1.05+9$ & $7.2-4$ \\
\hline & $3 / 2$ & $3 / 2$ & 40.05 & $3.83+8$ & $3.47+8$ & $2.2-4$ \\
\hline & $5 / 2$ & $3 / 2$ & 39.98 & $1.65+9$ & $1.47+9$ & $9.5-4$ \\
\hline \multirow[t]{2}{*}{$\left({ }^{3} \mathrm{P}\right)^{2} \mathrm{~S}$} & $1 / 2$ & $1 / 2$ & 37.80 & $2.75+8$ & $2.25+8$ & $1.0-4$ \\
\hline & $1 / 2$ & $3 / 2$ & 37.80 & $3.65+7$ & $3.64+7$ & $1.3-5$ \\
\hline \multirow[t]{4}{*}{$\left({ }^{3} \mathrm{P}\right)^{2} \mathrm{P}$} & $1 / 2$ & $1 / 2$ & 37.62 & $4.52+8$ & $4.00+8$ & $1.7-4$ \\
\hline & $1 / 2$ & $3 / 2$ & 37.62 & $4.06+8$ & $3.22+8$ & $1.5-4$ \\
\hline & $3 / 2$ & $1 / 2$ & 37.81 & $1.05+9$ & $6.03+8$ & 0.335 \\
\hline & $3 / 2$ & $3 / 2$ & 37.81 & $1.77+8$ & $2.17+8$ & 0.057 \\
\hline \multirow[t]{3}{*}{$\left({ }^{3} \mathrm{P}\right)^{2} \mathrm{D}$} & $3 / 2$ & $1 / 2$ & 37.68 & $2.57+8$ & $7.41+7$ & 0.057 \\
\hline & $3 / 2$ & $3 / 2$ & 37.69 & $9.94+8$ & $6.92+8$ & 0.221 \\
\hline & $5 / 2$ & $3 / 2$ & 37.86 & $1.34+9$ & $6.24+8$ & $8.7-4$ \\
\hline \multirow[t]{2}{*}{$\left({ }^{3} \mathrm{P}\right)^{4} \mathrm{~S}$} & $3 / 2$ & $1 / 2$ & 40.91 & $9.24+5$ & $9.19+5$ & 0.154 \\
\hline & $3 / 2$ & $3 / 2$ & 40.92 & $4.31+6$ & $4.30+6$ & 0.718 \\
\hline \multirow[t]{5}{*}{$\left({ }^{3} \mathrm{P}\right){ }^{4} \mathrm{P}$} & $5 / 2$ & $3 / 2$ & 40.24 & $1.54+8$ & $1.39+8$ & $1.3-3$ \\
\hline & $3 / 2$ & $3 / 2$ & 40.18 & $1.67+8$ & $1.55+8$ & $1.0-4$ \\
\hline & $3 / 2$ & $1 / 2$ & 40.17 & $1.08+8$ & $9.46+7$ & $6.5-4$ \\
\hline & $1 / 2$ & $3 / 2$ & 40.15 & $7.16+6$ & $4.84+6$ & $2.1-4$ \\
\hline & $1 / 2$ & $1 / 2$ & 40.14 & $3.46+7$ & $2.98+7$ & $4.3-5$ \\
\hline \multirow[t]{5}{*}{$\left({ }^{3} \mathrm{P}\right){ }^{4} \mathrm{D}$} & $5 / 2$ & $3 / 2$ & 40.46 & $5.08+7$ & $4.63+7$ & $1.0-3$ \\
\hline & $3 / 2$ & $3 / 2$ & 40.41 & $6.03+5$ & $7.56+5$ & $9.9-6$ \\
\hline & $3 / 2$ & $1 / 2$ & 40.40 & $7.87+7$ & $7.24+7$ & $1.3-3$ \\
\hline & $1 / 2$ & $3 / 2$ & 40.36 & $1.37+7$ & $1.36+7$ & 0.021 \\
\hline & $1 / 2$ & $1 / 2$ & 40.36 & $3.41+7$ & $3.36+7$ & 0.053 \\
\hline
\end{tabular}

of the radiative transition in this case is described by the ratio $\gamma$, called fluorescence yield, of the radiative transition probability between levels under investigation and the sum of the probabilities of all possible transitions (both radiative and autoionizing). For the decay of the $2 p^{5} 3 s 3 p^{2} L_{J}$ states one autoionization $\left(2 p^{6} \varepsilon l, l=0,2\right)$ and two radiative channels are possible. The calculated radiative transition wavelengths, probabilities, and fluorescence yields $\gamma$ for the transitions $2 p^{5} 3 s 3 p^{2} L_{J} \rightarrow 2 p^{5} 3 s^{2}{ }^{2} \mathrm{P}_{1 / 2,3 / 2}$ and $2 p^{5} 3 s 3 p$ ${ }^{2} L_{J} \rightarrow 2 p^{6} 3 p^{2} \mathrm{P}_{1 / 2,3 / 2}$ are presented in Tables 2 and 3 , respectively. The accuracy of these calculations can be estimated by comparing the calculated and measured wavelengths and by comparing the calculated transition probabilities in the length and velocity forms of electric dipole operator. From the data presented in Ta- bles 2 and 3 it is seen that the agreement between transition probabilities of the length and velocity forms is very good. Thus, we can conclude that the calculated transition probabilities are reliable and suitable for further applications. We do not know the measured values of wavelengths for the transitions under investigation. For comparison, the expected wavelengths $\lambda_{\exp }$ (in $\mathrm{nm}$ ) were calculated by using the experimental energy values $[4,6,37]$ (see Table 1 ). The accuracy of calculated wavelengths is not high, as the differences between them and expected ones reach up to $10 \mathrm{~nm}$. In [3], the wavelength of the transition $2 p^{5} 3 s\left({ }^{3} \mathrm{P}\right) 3 p$ ${ }^{2} \mathrm{P}_{3 / 2} \rightarrow 2 p^{5} 3 s^{2}{ }^{2} \mathrm{P}_{3 / 2}$ was $\lambda_{\exp }=434.3 \mathrm{~nm}$. The calculated value of the same transition in the present work is $446.7 \mathrm{~nm}$, and that obtained by using the experimental energies of levels is $440.3 \mathrm{~nm}$. Anyway, these values can be useful for the classification of future experimental data.

The data from Tables 1 and 2 can be used for the quantitative evaluation of the contribution made by radiative cascades from the $2 p^{5} 3 s 3 p L S J$ levels to the population of the $2 p^{5} 3 s^{2}{ }^{2} \mathrm{P}_{1 / 2,3 / 2}$ levels. As can be seen from Table 2, the fluorescence yields indicating the probability of transitions $2 p^{5} 3 s 3 p L S J \rightarrow 2 p^{5} 3 s^{2}$ ${ }^{2} \mathrm{P}_{1 / 2,3 / 2}$ are very small except for transitions from the $2 p^{5} 3 s\left({ }^{3} \mathrm{P}\right) 3 p{ }^{2} \mathrm{P}_{3 / 2}$ and ${ }^{2} \mathrm{D}_{3 / 2}$ levels. The corresponding contributions to the excitation cross-sections could be seen in excitation functions of the $2 p^{5} 3 s^{2}{ }^{2} \mathrm{P}_{1 / 2,3 / 2}$ levels at 34.97 and $35.08 \mathrm{eV}$ energies of exciting electron. The population density of these levels can be evaluated with the help of expression

$$
N_{1}=\frac{N_{0} N_{\mathrm{e}} v}{A_{10}+A_{1}^{\mathrm{a}}}\left(\sigma_{01}+\sigma_{02} \gamma_{21}\right)
$$

obtained by using the balance equations for three-level system in [16]. In (1), $N_{1}$ and $N_{0}$ are the population densities of the levels $2 p^{5} 3 s 3 p L S J$ and $2 p^{6} 3 s^{2} \mathrm{~S}_{1 / 2}$, respectively, $N_{\mathrm{e}}$ and $v$ are the density and velocity of exciting electrons, $\sigma_{01}$ and $\sigma_{02}$ are the excitation crosssections from the ground states to the $2 p^{5} 3 s^{2}{ }^{2} \mathrm{P}_{J 0}$ and $2 p^{5} 3 s 3 p L S J$ levels, respectively, $A_{10}$ and $A_{1}^{\mathrm{a}}$ are radiative and autoionization probabilities from the states $2 p^{5} 3 s^{2}{ }^{2} \mathrm{P}_{J 0}$, respectively, and $\gamma_{21}$ is the fluorescence yield of the transition $2 p^{5} 3 s 3 p L S J \rightarrow 2 p^{5} 3 s^{2}{ }^{2} \mathrm{P}_{J 0}$. The cross-sections for the excitation $2 p^{6} 3 s^{2} \mathrm{~S}_{1 / 2} \rightarrow$ $2 p^{5} 3 s^{2}{ }^{2} \mathrm{P}_{J 0}$ are investigated both experimentally (e. g. $[1,38])$ and theoretically [38]. The excitation crosssections of the states $2 p^{5} 3 s 3 p L S J$ were calculated in the present work by applying DW with exchange approximation. For a number of selected energies, they are presented in Table 4. One can see from Table 4 
Table 4. Excitation cross-sections (in $\mathrm{cm}^{2}$ ) calculated in distorted wave with exchange approximation for the transitions $2 p^{6} 3 s^{2} \mathrm{~S}_{1 / 2} \rightarrow 2 p^{5} 3 s\left(L_{1} S_{1}\right) 3 p L S J$ in $\mathrm{Na}$ for selected electron impact energies $E$ (in $\mathrm{eV}$ ).

\begin{tabular}{cccccc}
\hline$\left(L_{1} S_{1}\right) L S$ & $J$ & $E=30$ & $E=40$ & $E=50$ & $E=70$ \\
\hline$\left({ }^{1} \mathrm{P}\right)^{2} \mathrm{~S}$ & $1 / 2$ & $3.8-22$ & $2.5-21$ & $2.9-21$ & $1.6-21$ \\
\hline$\left({ }^{1} \mathrm{P}\right)^{2} \mathrm{P}$ & $1 / 2$ & $1.2-24$ & $8.2-24$ & $9.4-24$ & $5.3-24$ \\
& $3 / 2$ & $7.0-26$ & $2.5-25$ & $2.8-25$ & $1.7-24$ \\
\hline$\left({ }^{1} \mathrm{P}\right)^{2} \mathrm{D}$ & $3 / 2$ & $1.6-24$ & $5.8-24$ & $6.4-24$ & $3.8-24$ \\
& $5 / 2$ & $3.1-24$ & $1.1-23$ & $1.3-23$ & $7.4-24$ \\
\hline$\left({ }^{3} \mathrm{P}\right)^{2} \mathrm{~S}$ & $1 / 2$ & $4.0-21$ & $2.6-20$ & $3.0-21$ & $1.7-20$ \\
\hline$\left({ }^{3} \mathrm{P}\right)^{2} \mathrm{P}$ & $1 / 2$ & $2.5-21$ & $1.74-20$ & $2.0-20$ & $1.1-20$ \\
& $3 / 2$ & $6.9-22$ & $5.1-21$ & $5.5-21$ & $3.1-21$ \\
\hline$\left({ }^{3} \mathrm{P}\right)^{2} \mathrm{D}$ & $3 / 2$ & $7.1-22$ & $2.5-21$ & $2.9-21$ & $1.7-21$ \\
& $5 / 2$ & $1.7-21$ & $6.0-21$ & $6.7-21$ & $4.0-21$ \\
\hline$\left({ }^{3} \mathrm{P}\right)^{4} \mathrm{~S}$ & $3 / 2$ & $3.7-30$ & $1.4-29$ & $1.5-29$ & $8.9-30$ \\
\hline$\left({ }^{3} \mathrm{P}\right)^{4} \mathrm{P}$ & $5 / 2$ & $2.0-25$ & $7.1-25$ & $7.9-25$ & $4.7-25$ \\
& $3 / 2$ & $1.6-25$ & $5.6-25$ & $6.2-25$ & $3.7-25$ \\
& $1 / 2$ & $2.1-24$ & $1.4-23$ & $1.6-23$ & $8.9-24$ \\
\hline$\left({ }^{3} \mathrm{P}\right)^{4} \mathrm{D}$ & $5 / 2$ & $7.9-26$ & $2.9-25$ & $3.2-25$ & $1.9-25$ \\
& $3 / 2$ & $5.6-26$ & $2.0-25$ & $2.2-25$ & $1.3-25$ \\
& $1 / 2$ & $1.5-26$ & $9.8-26$ & $1,1-25$ & $6.3-26$ \\
\hline
\end{tabular}

that the excitation cross-sections of the $2 p^{5} 3 s\left({ }^{3} \mathrm{P}\right) 3 p$ ${ }^{2} \mathrm{~S}_{1 / 2},{ }^{2} \mathrm{P}_{1 / 2,3 / 2}$, and ${ }^{2} \mathrm{D}_{3 / 2,5 / 2}$ states are by about two orders of magnitude greater than those of the $2 p^{5} 3 s^{2}$ ${ }^{2} \mathrm{P}_{J 0}$ states. The contribution of the cascade populations $\Delta=\sigma_{02} \gamma_{21}$ can be obtained from (1) as follows:

$$
\begin{aligned}
& \Delta\left({ }^{2} \mathrm{P}_{3 / 2}\right)=0.48 \sigma\left(2 p^{6} 3 s \rightarrow 2 p^{5} 3 s\left({ }^{3} \mathrm{P}\right) 3 p^{2} \mathrm{P}_{3 / 2}\right) \\
& +0.015 \sigma\left(2 p^{6} 3 s \rightarrow 2 p^{5} 3 s\left({ }^{3} \mathrm{P}\right) 3 p^{2} \mathrm{D}_{3 / 2}\right) \\
& \Delta\left({ }^{2} \mathrm{P}_{1 / 2}\right)=0.01 \sigma\left(2 p^{6} 3 s \rightarrow 2 p^{5} 3 s\left({ }^{3} \mathrm{P}\right) 3 p^{2} \mathrm{P}_{1 / 2}\right) \\
& +0.1 \sigma\left(2 p^{6} 3 s \rightarrow 2 p^{5} 3 s\left({ }^{3} \mathrm{P}\right) 3 p^{2} \mathrm{D}_{3 / 2}\right)
\end{aligned}
$$

By using the excitation cross-section values from Table 4 , these contributions are obtained: $\Delta\left({ }^{2} \mathrm{P}_{3 / 2}\right)=$ $3.3 \cdot 10^{-22} \mathrm{~cm}^{2}, \quad \Delta\left({ }^{2} \mathrm{P}_{1 / 2}\right)=7.3 \cdot 10^{-22} \mathrm{~cm}^{2}$ and $\Delta\left({ }^{2} \mathrm{P}_{3 / 2}\right)=2.4 \cdot 10^{-21} \mathrm{~cm}^{2}, \Delta\left({ }^{2} \mathrm{P}_{1 / 2}\right)=4.3 \cdot 10^{-22} \mathrm{~cm}^{2}$ for the impact energies of 35 and $40 \mathrm{eV}$, respectively. Comparison of these data with the excitation cross-section of the $2 p^{5} 3 s^{2}{ }^{2} \mathrm{P}_{1 / 2,3 / 2}$ levels of about $1.5 \cdot 10^{-18} \mathrm{~cm}^{2}$ shows that the radiative cascades themselves should not effect significantly the population of $2 p^{5} 3 s^{2}{ }^{2} \mathrm{P}_{1 / 2,3 / 2}$ states.

\section{Conclusions}

The energy spectra of $2 p^{5} 3 s^{2}{ }^{2} \mathrm{P}_{1 / 2,3 / 2}$ and $2 p^{5} 3 s 3 p$ $L S J$ states are calculated by using highly accurate configuration interaction wavefunctions. The contributions of all configurations with the average weights higher than $2.0 \cdot 10^{-8}$ from the set of 13241 and 9500 of admixed configurations is taken into account. Comparison of the calculated energies with other available data shows that experimental energy values stand between the present data and those obtained in [13]. The calculated autoionization and radiative decay probabilities for the $2 p^{5} 3 s 3 p L S J$ levels are used to obtain the fluorescence yields for the $2 p^{5} 3 s 3 p L S J \rightarrow 2 p^{6} 3 p$ ${ }^{2} \mathrm{P}_{1 / 2,3 / 2}$ radiative transitions. The evaluations based on these data and calculated excitation cross-sections allow us to come to a conclusion that the radiative cascades themselves should not effect significantly the population of the $2 p^{5} 3 s^{2}{ }^{2} \mathrm{P}_{1 / 2,3 / 2}$ states.

\section{Acknowledgements}

This work was supported, in part, by the INTAS under grant 03-51-4706 (A. B.) and Taiwan-Baltic project (A. K. and P. B.).

\section{References}

[1] V.A. Borovik, L.L. Shimon, and A.A. Borovik, in: $A b-$ stracts of 38th EGAS Conference, Naples, Italy (2006) p. 174.

[2] O. Zatsarinny and K. Bartschat (2007, private communication).

[3] T. Nandi, M.B. Kurup, K.G. Prasad, and P. Rao, J. Phys. B 27, 1975 (1994)

[4] H.W. Wolf, K. Radler, and R. Haensel, Z. Phys. 257, 353 (1972).

[5] J.P. Connerade, W.R.S. Garton, and M.W.D. Mansfield, Astrophys. J. 165, 203 (1971).

[6] J. Sugar, T.B. Lucatorto, T.J. McIlrath, and A.W. Weiss, Opt. Lett. 4, 109 (1979).

[7] M.A. Baig, M.S. Mahmood, K. Sommer, and J. Hormes, J. Phys. B 27, 389 (1994).

[8] D.J. Pegg, H.H. Haselton, R.S. Thoe, P.M. Griffin, M.D. Brown, and I.A. Sellin, Phys. Rev. A 12, 1330 (1975).

[9] K.J. Ross, T.W. Ottley, V. Pejcev, and D. Rassi, J. Phys. B 9, 3237 (1976).

[10] E. Breuckmann, B. Breuckmann, W. Melhorn, and W. Schmitz, J. Phys. B 10, 3135 (1977).

[11] Yu.V. Zhmenjak, V.C. Vukstich, and I.P. Zapesochny, Pis'ma Zh. Eksp. Teor. Fiz. [JETP Lett.] 35, 321 (1982). 
[12] Ch. Froese Fischer, Phys. Rev. A 34, 1667 (1986).

[13] O.I. Zatsarinny and L.A. Bandurina, J. Phys. B 26, 3765 (1993).

[14] A.A. Bandzaitis, A.V. Kuplyauskene, Z.I. Kuplyauskis, and V.J. Tutlis, Lietuvos Fizikos Rinkinys [Sov. Phys. Collection] 19, 187 (1979).

[15] G.N. Ogurtsov, V.M. Mikoushkin, I.P. Flaks, A.V. Kuplyauskene, and Z.I. Kuplyauskis, Opt. Spectrosk. [Opt. Spectrosc. (USSR)] 54, 230 (1983).

[16] A. Kupliauskienè, P. Bogdanovich, A.A. Borovik, O. Zatsarinny, and K. Bartschat, J. Phys. B. 39, 591 (2006).

[17] P. Bogdanovich and R. Karpuškienè, Lithuanian J. Phys. 39, 193 (1999).

[18] P. Bogdanovich, R. Karpuškienè, and I. Martinson, Phys. Scripta 67, 44 (2003).

[19] P. Bogdanovich, R. Karpuškienè, and I. Martinson, Nucl. Instrum. Methods B 205, 70 (2003).

[20] P. Bogdanovich, R. Karpuškienè, and A. Udris, Phys. Scripta 67, 395 (2003).

[21] R. Karpuškienė and P. Bogdanovich, J. Phys. B 36, 2145 (2003)

[22] P. Bogdanovich, R. Karpuškienè, and A. Udris, At. Data Nucl. Data Tables 89, 45 (2005).

[23] P. Bogdanovich and R. Karpuškienè, Nucl. Instrum. Methods B 235, 174 (2005).

[24] C. Froese Fischer, Comput. Phys. Commun. 43, 355 (1987).
[25] R. Karpuškienè, R. Karazija, and P. Bogdanovich, Phys. Scripta 64, 333 (2001).

[26] P. Bogdanovich and R. Karpuškiene, Comput. Phys. Commun. 134, 321 (2001).

[27] P. Bogdanovich, Nucl. Instrum. Methods B 235, 92 (2005).

[28] P. Bogdanovich, R. Karpuškienè, and A. Momkauskaite, Comput. Phys. Commun. 172, 133 (2005).

[29] P. Bogdanovich, R. Karpuškienè, and A. Momkauskaitè, Comput. Phys. Commun. 143, 174 (2002)

[30] P. Bogdanovich and A. Momkauskaite, Comput. Phys. Commun. 157, 217 (2004)

[31] G. Gaigalas, Lithuanian J. Phys. 42, 73 (2002).

[32] C. Froese Fisher, M.R. Godefroid, and A. Hibbert, Comput. Phys. Commun. 64, 486 (1991).

[33] C. Froese Fisher and M.R. Godefroid, Comput. Phys. Commun. 64, 501 (1991).

[34] R.W. Cowan, The Theory of Atomic Structure and Spectra (University of California, 1981).

[35] A. Kupliauskiene, Phys. Scripta 75, 524 (2007).

[36] A. Kupliauskienè and V. Tutlys, Lithuanian J. Phys. 43, 35 (2003).

[37] D.E. Holmgren, D.J. Walker, D.A. King, and S.E. Harris, Phys. Rev. A 31, 677 (1985).

[38] B. Feuerstein, A.N. Grum-Grzhimailo, and W. Mehlhorn, J. Phys. B 32, 539 (1998).

\title{
RADIACINIAI ŠUOLIAI TARP ŽEMIAUSIŲ Na ATOMO AUTOJONIZACINIŲ BŪSENŲ
}

\author{
A. Kupliauskiené ${ }^{\text {a }}$, P. Bogdanovičius ${ }^{\text {a }}$, A. Borovik ${ }^{\text {b }}$ \\ ${ }^{\text {a }}$ VU Teorinès fizikos ir astronomijos institutas, Vilnius, Lietuva \\ b Ukrainos NMA Elektronu fizikos institutas, Užgorodas, Ukraina
}

\section{Santrauka}

Užregistruotame $\mathrm{Na}$ atomo sužadinimo i $2 p^{5} 3 s^{2}{ }^{2} \mathrm{P}_{1 / 2,3 / 2}$ būsenas skerspjūvyje ties $32-33$ ir 36,5-40 eV žadinančio elektrono energijomis pastebėti maksimumai, kurių negalima paaiškinti $2 p^{5} 3 s 3 p L S J$ rezonansų susidarymu. Norint išsiaiškinti jų priežastį, atlikti labai tikslūs $2 p^{5} 3 s^{2}{ }^{2} \mathrm{P}_{1 / 2,3 / 2}$ ir $2 p^{5} 3 s 3 p L S J$ būsenų energijos spektrų ir radiacinių šuolių tarp jų tikimybių skaičiavimai. Sužadinimo i $2 p^{5} 3 s^{2}{ }^{2} \mathrm{P}_{1 / 2,3 / 2}$ skerspjūvio priedui dèl kaskadų iš $2 p^{5} 3 s 3 p L S J$ ivvertinti taip pat apskaičiuotos $2 p^{5} 3 s^{2}$
${ }^{2} \mathrm{P}_{1 / 2,3 / 2}$ ir $2 p^{5} 3 s 3 p L S J$ būsenų autojonizacijos tikimybès, fluorescencijos našumai ir sužadinimo i $2 p^{5} 3 s 3 p L S J$ skerspjūviai. Rasti 2 lygmenys $2 p^{5} 3 s\left({ }^{3} \mathrm{P}\right) 3 p^{2} \mathrm{P}_{3 / 2}$ ir ${ }^{2} \mathrm{D}_{3 / 2}$, iš kurių fluorescencijos našumai dideli, ir būtų galima tikètis pastebimo kaskadų indèlio. Atlikus îvertinimus, panaudojant apskaičiuotus sužadinimo skerspjūvius, tenka padaryti išvadą, kad šuolių iš $2 p^{5} 3 s 3 p L S J$ skerspjūvio priedas $2 p^{5} 3 s^{2}{ }^{2} \mathrm{P}_{1 / 2,3 / 2}$ sužadinimo skerspjūviui yra per mažas maksimumams eksperimentiniame spektre paaiškinti. 